\title{
Emotional Freedom Technique Dalam Mengatasi Kecemasan Siswa Menghadapi Ujian
}

\author{
${ }^{1}$ Idriani Idris, ${ }^{2}$ Idris \\ ${ }^{1}$ Universitas Negeri Gorontalo \\ ${ }^{2}$ SMP Negeri 1 Galesong Utara \\ email: idriani_ck09@yahoo.co.id
}

\begin{abstract}
Abstrak
Pada prinsipnya, ujian bertujuan untuk mengetahui perubahan tingkah laku, baik potensial maupun aktual dan kecakapan baru yang dicapai oleh siswa setelah mengikuti proses pembelajaran. Tetapi sering kali siswa menganggap ujian sebagai masalah besar sehingga timbul kecemasan ketika harus menghadapi ujian. Kecemasan tersebut disebabkan kurang rileksnya tubuh dan pikiran saat menghadapi suatu persoalan sehingga menjadi tegang seperti adanya persepsi yang kuat dalam diri siswa, di mana nilai ujian yang baik merupakan tanda kesuksesan belajar sedangkan nilai ujian yang rendah merupakan kegagalan dalam belajar. Adanya persepsi tersebut membuat siswa menganggap bahwa nilai satu-satunya indikator dalam melihat keberhasilan sehingga prestasi belajar siswa tidak sesuai dengan harapan. Oleh karena itu upaya mencegah atau meminimalisir kecemasan siswa tersebut melalui emotional freedom technique. Prinsip kerja Emotional freedom technique, adalah menyelaraskan dan memperbaiki kembali sistem energi dalam tubuh yang tergangu, lewat stimulasi pada titik-titik energi tubuh yang disebut sebagai meridian dengan menggunakan tapping (ketukan ringan). Prosedur emotional freedom technique yaitu the set up (the set up words), the tune-in, the tapping, the nine gamut prosedure dan the tapping again.
\end{abstract}

Kata Kunci: Kecemasan, Emotional Freedom Tecnique

\section{PENDAHULUAN}

Keberhasilan pendidikan nasional tidak terlepas dari proses pembelajaran di sekolah. Harapan keberhasilan pendidikan tersebut berlandaskan pada tujuan nasional, dalam upaya mencapai tujuan pendidikan tersebut, banyak siswa yang mengalami berbagai kendala. Salah satunya adalah kecemasan siswa dalam menghadapi ujian yang memungkinkan prestasi belajar siswa tidak sesuai dengan harapan. Pada umumnya siswa yang mengalami kecemasan, ketika siswa tersebut dihinggapi rasa khawatir dan perasaan takut. Kecemasan dalam menghadapi ujian tidak hanya dialami oleh siswa yang kecerdasannya rendah, tetapi siswa yang kecerdasan dan motivasinya tinggipun dapat mengalaminya. Dimana pada prinsipnya, ujian bertujuan untuk mengetahui perubahan tingkah laku, baik potensial maupun aktual dan kecakapan baru yang dicapai oleh siswa setelah mengikuti proses pembelajaran. Tetapi sering kali siswa menganggap ujian sebagai masalah besar sehingga timbul kecemasan ketika harus menghadapi ujian.

Corey mengungkapkan bahwa "kecemasan dapat ditimbulkan oleh kondisi kurang rileksnya tubuh dan pikiran saat menghadapi suatu persoalan sehingga menjadi tegang”. 
Selanjutnya untuk mengurangi kecemasan tersebut diperlukan penemuan-penemuan positif yang berlawanan dengan respon negatif (kecemasan) tersebut. ${ }^{1}$

Dalam upaya menentukan apakah siswa mengalami kecemasan atau tidak, diperlukan penelaahan yang seksama dengan cara mengenali symptom atau gejala beserta faktor-faktor yang melatarbelakanginya. Adapun faktor yang menyebabkan timbulnya kecemasan pada diri siswa dalam menghadapi ujian yaitu, siswa memandang ujian yang dihadapinya dirasa sulit dan tidak sanggup untuk menyelesaikannya dengan baik, siswa lebih beriorentasi untuk mendapatkan nilai yang tinggi, sehingga untuk menggapai harapan tersebut membuat siswa merasa cemas saat menghadapi ujian atau ulangan, baik ulangan harian, ujian tengah semester, ujian akhir semester serta ujian nasional, perasaan kurang yakin bisa menjawab butir soal, takut jawabannya salah, takut nilai dan prestasinya turun, takut tidak lulus, dan alasan lain yang merupakan penyebab kecemasan yang bersumber dari dalam diri siswa. Apabila kecemasan pada siswa tidak mendapatkan penanganan yang tepat, maka diprediksikan prestasi belajar siswa menjadi tidak optimal dan kemungkinan tidak lulus dalam ujian akibat merasa cemas, oleh karena itu upaya menyelesaikan kecemasan siswa dalam mengikuti ujian sangat diperlukan.

\section{EMOTIONAL FREEDOM TECHNIQUE (EFT)}

\section{Sejarah Emotional Freedom Technique}

Energi psikologi dipopulerkan oleh Dr. Roger Callahan di tahun 1980-an, merupakan penemuannya ketika mengobati pasien bernama Mary yang mengalami water fhobia menggunakan teknik TFT (Thougt Field Therapy). Dengan penemuannya, yaitu mengetuk (tapping) dengan ujung jarinya kebagian bawah kelopak mata Mary, dalam waktu kurang dari satu menit Mary mengatakan rasa tidak enak di perutnya akibat dari fobia itu hilang. Dr. Callahan sama herannya dengan Mary, lalu ia mencoba teknik yang sama ke ratusan pasiennya, dan hasilnya adalah berhasil. Selanjutnya pada awal tahun 1990-an salah satu siswa Dr. Callahan, yang bernama Gery Craig, menyederhanakan algoritma TFT menjadi EFT dimana prosesnya dibuat lebih sederhana secara universal agar bisa diterapkan untuk semua permasalahan mental, emosional dan fisik. ${ }^{2}$

2. Pengertian Emotional Freedom Technique (EFT)

Menurut Craig "Emotional Freedom Technique merupakan teknik penyembuhan emosional yang juga ternyata dapat menyembuhkan gejala-gejala penyakit fisik". ${ }^{3} \mathrm{Hal}$ ini berdasar pada revolusi yang berkembang dalam keyakinan psikologi konvensional yang menjelaskan bahwa "segala emosi negatif yang muncul dapat merusak energi sistem dalam tubuh". EFT dilakukan dengan mengetukkan dua ujung jari pada beberapa lokasi tubuh. Ketukan-ketukan tersebut bertujuan untuk menyeimbangkan energi meredian dalam tubuh ketika terjadi gejala-gejala

${ }^{1}$ Corey, G, Teori dan Praktek Konseling dan Psikoterapi. (Bandung: Rafika Pratama, 2007), hlm 209.

2 Juwono, S. Buku Terapi EFT (Emotional Freedom Technique).(Yogyakarta: NQ. Publising, 2012), hlm 16.

${ }^{3}$ Saputra, A. EFT (Emotional Freedom Tecnique). (Yogyakarta: Genius Publisher, 2011) hlm 78. 
kemunduran fisik dan emosional yang menggangu memori secara aktual tetap sama, namun gejala penyakit hilang.

Craig mengemukakan Emotional Freedom Technique (EFT) adalah sebuah terapi psikologi praktis yang dapat menangani banyak penyakit, baik itu penyakit fisik dan penyakit psikologis (masalah pikiran dan perasaan) ${ }^{4}$. Artinya EFT merupakan versi psikologi dari terapi akupunktur yang tidak menggunakan jarum, melainkan dengan menyelaraskan sistem energi tubuh pada titik-titik meridian di tubuh, dengan cara mengetuk (tapping) dengan ujung jari. Teknik ini sangat mudah dipelajari dan dapat diterapkan di mana saja, dan untuk siapa saja.

Menurut teori ilmu EFT, penyebab segala macam emosi negatif adalah terganggunya sistem energi tubuh dan emosi-emosi negatif yang tak terselesaikan, menjadi penyebab utama pada hampir semua penyakit fisik.

\section{Prinsip Kerja Emotional Freedom Technique (EFT)}

EFT didasarkan pada keyakinan bahwa masalah emosional berakar dari gangguan energi tubuh. Maka, intervensi pada sistem tubuh dengan menstimulus melalui tapping/ketukan ringan dengan jari di delapan belas titik meredian tubuh untuk mengatasi hampir semua hambatan emosi dan fisik. ${ }^{5}$ Titik-titik energi/meridian akan menyelaraskan energi tubuh, mengubah kimiawi otak dan selanjutnya mengubah kondisi emosi menjadi lebih positif. Energi dalam tubuh sangat berperan, karena gangguan pada energi tubuh akan menyebabkan gangguan pada emosi atau fisik.

Ketika seseorang mengalami hambatan emosional seperti marah, kecewa, sedih, cemas, stress, trauma dsb, aliran energi di dalam tubuh yang melalui titik meredian tubuh akan terganggu. Juwono menyatakan untuk menghilangkan hambatanhambatan emosi, hanya perlu memperbaiki gangguan aliran di titik meredian dengan cara mengetukkan jari dengan cara tertentu sesuai teknik EFT, untuk melakukan ketukan pada delapan belas titik meredian tubuh hanya memerlukan lima prosedur yang sederhana dan mudah diingat, yang dinamakan resep dasar (basic recipe). Prosedur ini dapat digunakan untuk mengatasi hampir semua masalah emosi negatif dan fisik. ${ }^{6}$

\section{Proses Terjadinya Emosi Negatif Menurut EFT}

Secara teoritis menurut EFT, beberapa ingatan (sadar maupun bawah sadar) tentang masa lalu dapat membangkitkan ganguan psikologis, tetapi proses ini tidak berjalan secara langsung, melainkan ada "proses antara" yang dinamakan "discruption of body energy system". Craig mengambarkan tergangunya sistem energi tubuh langsung menyebabkan ganguan emosi. Proses ini bisa dijelaskan melalui gambar berikut. ${ }^{7}$

\footnotetext{
${ }^{4}$ Zaki, M. 5 Terapi Sehat. (Jakarta: PT. Elex Media Komputindo, 2012) hlm 119

${ }^{5}$ Saputra, A. EFT (Emotional Freedom Tecnique). (Yogyakarta: Genius Publisher, 2011) hlm 87.

6 Juwono, F. Buku Terapi EFT (Emotional Freedom Technique). (Yogyakarta: NQ. Publising, 2012) hlm 21.

Saputra, A. EFT (Emotional Freedom Tecnique). (Yogyakarta: Genius Publisher, 2011) hlm 91.
} 


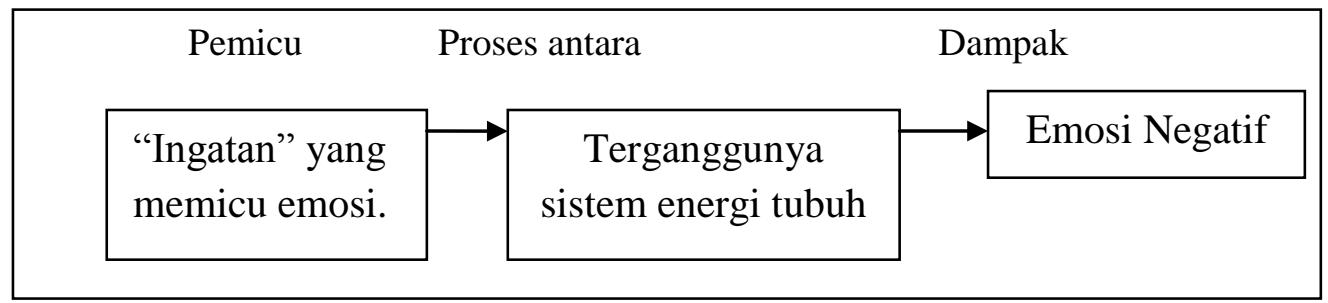

5. Tahap-Tahap Emotional Freedom Technique (EFT)

Menurut Zainuddin, Emotional Freedom Technique (EFT) dapat dilakukan melalui lima tahap sebagai berikut: ${ }^{8}$

1) The set up, yaitu kata-kata sugesti yang dapat memberikan keyakinan atau kepasrahan untuk dapat mengelola kecemasan, agar aliran tubuh yang dirasakan dapat diarahkan dengan tepat dan untuk menetralisasi perlawanan psikologis. Untuk dapat melakukan the set up tambahkanlah kata "Ya Tuhan meskipun saya .... dan .... saya menerima dan mencintai diri saya sepenuhnya. Kemudian menekan dada tepatnya dibagian sore spot atau dua ujung jari dibagian karate chop.

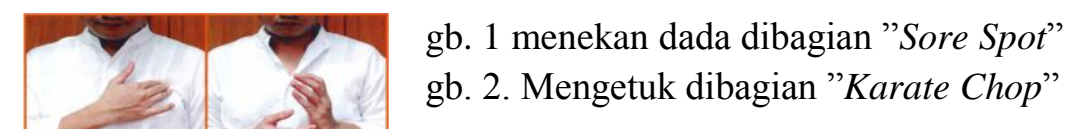

2) The tune-in yaitu untuk menetralisasi emosi negatif atau sakit fisik yang dirasakan, dengan mengulang-ulang kata pengingat yang mewakili emosi negatif yang dirasakan. Kata pengingat dapat diambil dari kata pada saat set up atau mengganti kata pengingatnya dengan kalimat "Saya ikhlas, saya pasrah pada-Mu ya Allah" atau "Saya mencintai dan menerima diri saya sepenuhnya ya Allah".

3) The tapping adalah mengetuk ringan dengan dua ujung jari pada titik tertentu di bagian tubuh terus tune in (mengucapkan apa yang ingin dilakukan pikiran anda saat ini). Titik-titik tersebut yaitu:

Cr $=$ Crown

Pada titik dibagian atas kepala

$E B=$ Eye Brow

Pada titik permulaan alis mata

$S E=$ Side of the Eye

Diatas tulang disamping mata

$U E=$ Under the Eye

$2 \mathrm{~cm}$ dibawah kelopak mata

$U N=$ Under The Nose

Tepat dibawah hidung

Ch $=$ Chin

Diantara dagu dan bagian bawah bibir $C B=$ Collar Bone

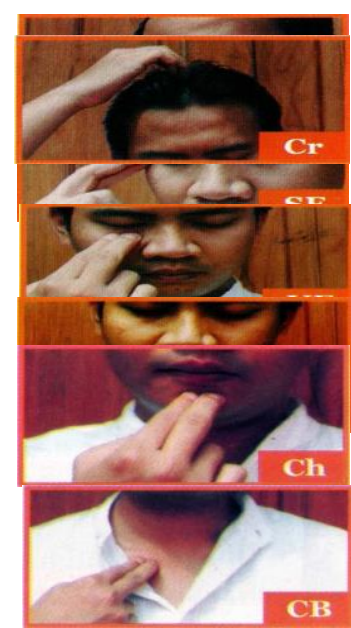

${ }^{8}$ Safaria, T. \& Nofrans, E.S. Manajemen Emosi. (Jakarta: Bumi Aksara, 2009) hlm 181. 
Diujung tempat bertemunya tulang - dada, dan tulang rusuk pertama

$U A=$ Under The Arm

Dibawah ketiak

$B N=$ Bellow Niple

$2,5 \mathrm{~cm}$ dibawah puting susu (pria) atau diperbatasan antara tulang dada

$I H=$ Inside of Hand

Dibagian dalam tangan yang berbatasan dengan telapak tangan

$\mathrm{OH}=$ Outside of Hand

Dibagian luar tangan yang berbatasan dengan telapak tangan

$T h=$ Thumb

Ibu jari disamping luar bagian bawah kuku

$I F=$ Index Finger

Jari telunjuk disamping luar bagian bawah kuku $M F=$ Middle Finger

Jari tengah samping luar bagian bawah kuku

$R F=$ Ring Finger

Jari manis disamping luar bagian bawah kuku

$B F=$ Baby Finger

Dijari kelingking disamping luar bagian bawah

kuku

$K C=$ Karate Chop

Disamping telapak tangan

$G S=$ Gamut Spot

Dibagian antara perpanjangan tulang jari manis

dan kelingking

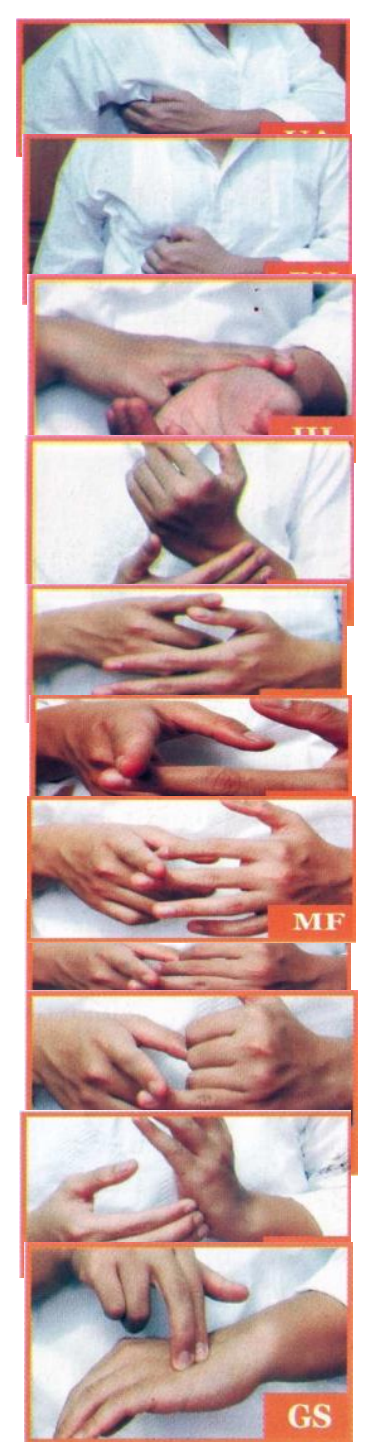

4) Nine gamut procedure adalah sembilan gerakan untuk merangsang otak, yaitu a) menutup mata, b) membuka mata. c) mata digerakkan dengan kuat ke kanan bawah, d) mata digerakkan dengan kuat ke kiri bawah, e) memutar bola mata searah jarum jam, f) memutar bola mata berlawanan arah jarum jam, g) bergumam dengan berirama selama dua detik. h) menghitung 1, 2, 3, 4, 5, 6, 7, 8, i) bergumam lagi seperti langkah ke-7

5) The tapping again adalah mengulang lagi the tapping dengan mengambil nafas panjang dan menghembuskannya. 


\section{Kelebihan Emotional Freedom Technique (EFT)}

Craig menjelaskan kelebihan Emotional Freedom Technique: ${ }^{9}$

1) Menyembuhkan dengan sangat cepat. Artinya EFT menyembuhkan gangguan emosional yang bisa lenyap dalam hitungan menit atau jam.

2) EFT hanya membutuhkan satu atau dua sesi saja untuk mendapatkan kesembuhan. Artinya EFT bisa dilakukan tanpa memerlukan sesi yang banyak.

3) Ketika emosi negatif sudah dapat dihilangkan dengan EFT, maka masalahmasalah fisik mulai hilang dengan sendirinya. Artinya jika emosi negatif sudah tenetralisir maka masalah fisik juga akan hilang.

4) EFT tidak perlu menggunakan alat-alat lain, hanya menggunakan tapping.

5) Didukung oleh sejumlah penelitian ilmiah. Artinya EFT sudah terbukti dan tidak diragukan lagi.

6) Digunakan oleh lebih dari 100.000 praktisi di seluruh dunia. Dengan hasil yang spektakuler.

\section{KECEMASAN SISWA MENGHADAPI UJIAN}

\section{Defenisi Kecemasan Siswa Menghadapi Ujian}

Kecemasan atau dalam bahasa inggrisnya "anxiety" berasal dari bahasa latin "angustus" yang berarti kaku, dan "ango, anci" yang berarti mencekik. Freud menyatakan defenisi "kecemasan adalah suatu keadaan tegang yang memperingatkan adanya ancaman bahaya, yakni sinyal bagi ego yang akan terus meningkat jika tindakan-tindakan yang layak untuk mengatasi ancaman bahaya itu tidak diambil". ${ }^{10}$ Sementara itu Frederick mengemukakan definisi tentang Kecemasan ujian adalah sebuah kondisi psikologis dan fisiologis yang ditandai oleh ketidaknyaman dalam manifestasi kognitif, emosional, dan perilaku. Komponen-komponen ini bergabung untuk membuat perasaan tidak menyenangkan yang biasanya dikaitkan dengan kegelisahan, ketakutan, atau khawatir. ${ }^{11}$ Dengan demikian dapat disimpulkan kecemasan menghadapi ujian dalam penelitian ini adalah suatu kondisi psikologis dan fisiologis siswa yang tidak menyenangkan yang ditandai pikiran, perasaan dan aktivitas fisik yang tidak terkendali yang memicu timbulnya rasa cemas saat menghadapi ujian.

2. Faktor-Faktor yang Mempengaruhi Kecemasan Siswa dalam Menghadapi Ujian Ellis, dkk ${ }^{12}$ menyatakan terdapat dua faktor yang menyebabkan adanya kecemasan, yaitu (1) pengalaman negatif merupakan hal yang tidak menyenangkan pada masa lalu mengenai peristiwa yang dapat terulang lagi pada masa mendatang.

9 Juwono, F. Buku Terapi EFT (Emotional Freedom Technique). (Yogyakarta: NQ. Publising, 2012) hlm 87.

${ }^{10}$ Corey, G. Teori dan Praktek Konseling dan Psikoterapi. (Bandung: Rafika Pratama, 2007) hlm 17.

${ }^{11}$ Frederick, J. Relaxation-Induence Anxiety: Paradoxical Anxiety Enhancement Due To Relaxation Training. (Jurnal Of Counsulting and Clinical Psychology. 1983) hlm 82.

${ }^{12}$ Ghufron, N. \& Rini, R.S. Teori-Teori Psikologi. (Jakarta: Ar-Ruzz Media, 2011) hlm 145. 
Artinya apabila individu tersebut menghadapi situasi atau kejadian yang sama dan juga tidak menyenangkan pada masa lalu, misalnya pernah gagal dalam tes, maka hal tersebut akan memicu kecemasan tersendiri dalam ujian dan menghadapi tes selanjutnya, (2) pikiran yang tidak rasional merupakan kepercayaan atau keyakinan individu yang merupakan buah pikiran yang keliru, yaitu: a) kegagalan katastropik yaitu adanya asumsi dari diri individu bahwa akan terjadi sesuatu yang buruk pada dirinya. Artinya individu selalu berfikir bahwa setiap akan ujian akan terjadi hal yang buruk kepadanya, b) kesempurnaan, dimana individu menjadikan ukuran kesempurnaan sebagai target dan sumber inspirasi baginya, c) persetujuan yaitu adanya keyakinan yang salah didasarkan pada ide bahwa terdapat hal virtual yang tidak hanya diinginkan, tetapi juga untuk mencapai persetujuan sesama teman atau siswa, d) generalisasi yang tidak tepat yaitu generalisasi yang berlebihan. Hal ini terjadi pada orang yang mempunyai sedikit pengalaman.

\section{Bentuk-Bentuk Kecemasan}

Menurut Spilberger dalam Sutanaya, kecemasan terbagi atas dua bentuk, yaitu: 1) sebagai trait anxiety, kecemasan sebagai suatu trait (trait anxiety), yaitu kecenderungan pada diri seseorang untuk merasa terancam oleh sejumlah kondisi yang sebenarnya tidak berbahaya. Kecemasan dalam kategori ini lebih disebabkan karena kepribadian individu tersebut memang mempunyai potensi cemas (bersifat bawaan) dibandingkan dengan individu lain, 2) state anxiety, kecemasan sebagai suatu keadaan (state anxiety), yaitu keadaan dan kondisi emosional sementara pada diri seseorang yang ditandai dengan perasaan tegang dan khawatir yang dirasakan dengan sadar serta bersifat subjektif dan meningginya aktivitas sistem syaraf otonom, sebagai suatu keadaan yang berhubungan dengan situasi-situasi lingkungan khusus ${ }^{13}$. Sedangkan menurut Corey terdapat tiga bentuk kecemasan ${ }^{14}$, yakni 1) kecemasan realitas, takut akan bahaya-bahaya nyata dari dunia luar atau lingkungan, 2) kecemasan neurotik adalah rasa takut akibat dari insting (dorongan id) yang akan dilepas dari kendali dan menyebabkan seseorang berbuat sesuatu yang bisa membuatnya dihukum. Kecemasan neurotik ini berkembang berdasarkan pengalaman yang diperolehnya pada masa kanak-kanak terkait dengan hukuman dan ancaman dari orang tua maupun orang lain yang mempunyai otoritas jika dia melakukan kegiatan impulsif, 3) kecemasan moral adalah rasa takut terhadap suara hati. Bedasarkan yang dikemukan diatas dapat disimpulkan bentuk-bentuk kecemasan, ada yang bersifat bawaan, dan ada juga yang bersifat sementara, ketika kinerja syaraf otonom meningkat maka seseorang akan merasa cemas.

${ }^{13}$ Sutanaya, A. Kecemasan Siswa Terhadap Sekolah ditinjau dari motivasi berprestasi dan konsep diri akademik pada siswa SMA Negeri Denpasar Tahun 2005. Tesis. Singgaraja: Unit Penerbitan IKIP Negeri Singaraja.

${ }^{14}$ Corey, G. Teori dan Praktek Konseling dan Psikoterapi. Bandung: Rafika Pratama, 2007) hlm 117. 


\section{Aspek-Aspek Kecemasan Siswa dalam Menghadapi Ujian}

Menurut Bucklew dalam Sutanaya upaya mengenali gejala kecemasan dapat ditinjau melalui dua aspek ${ }^{15}$, yaitu: 1) aspek psikologis yaitu kecemasan ujian yang berwujud sebagai gejala-gejala kejiwaan. Artinya beberapa gejala psikologis atau kejiwaan menunjukkan siswa berada dalam situasi yang cemas saat menghadapi ujian. Adapun indikatornya yaitu: tegang, khawatir, sulit berkonsentrasi, tidak tenang, takut dan gelisah, 2) aspek fisiologis adalah kecemasan yang sudah mempengaruhi atau terwujud pada gejala-gejala fisik, terutama pada fungsi dan sistem syaraf. Artinya beberapa gejala fisik yang ada menunjukkan siswa berada dalam situasi yang cemas saat menghadapi ujian. Adapun indikatornya, yaitu: berkeringat dingin, gemetar, tidak dapat tidur, sakit kepala dan jantung berdebar-debar.

Menurut Cassabro manifestasi kecemasan ujian (test anxiety) terwujud dalam tiga aspek ${ }^{16}$ yaitu: 1) manifestasi kognitif, yang terwujud dalam pikiran siswa, seringkali memikirkan tentang malapetaka atau kejadian buruk yang akan terjadi. Adapun indikator manifestasi kognitif dalam kecemasan menghadapi ujian yaitu: a) sulit konsentrasi yang ditunjukkan dengan kesulitan dalam membaca dan memahami pertanyaan ujian, kesulitan berfikir secara sistematis, kesulitan mengingat kata kunci dan konsep saat menjawab pertanyaan essai atau uraian, b) bingung, yaitu perasaan yang timbul saat siswa harus mengambil suatu keputusan yang sulit dalam menjawab soal saat ujian oleh karena terdapat beberapa alternatif jawaban yang menurutnya benar atau salah karena pikirannya, c) mental blocking yaitu, hambatan secara mental/psikologis yang menyelubungi pikiran sehingga tidak bisa berfikir dengan tenang, 2) manifestasi afektif (perasaan) adalah kecemasan yang muncul sebagai akibat siswa merasakan perasaan yang berlebihan saat menghadapi ujian yang diwujudkan dalam bentuk perasaan khawatir, gelisah dan takut dalam menghadapi ujian. Adapun indikator manifestasi afektif yaitu: a) khawatir adalah perasaan tergangu akibat bayangan/pikiran buruk yang kita buat sendiri, yang belum terjadi pada diri kita, b) takut merupakan respon terhadap suatu bahaya yang timbul saat ini. Rasa takut itu membuat individu menjadi merasa kecil dan tidak berdaya, membuat menjadi rapuh dan mengkerut serta membuat individu selalu menghindar terhadap suatu persoalan yang terjadi, c) gelisah, adalah kondisi individu yang hatinya tidak tentram karena suatu keadaan yang tidak nyaman, 3) perilaku motorik (Gerak), adalah gerakan tidak menentu yang dilakukan individu seperti gemetar ketika berada dalam situasi cemas. Gemetar merupakan suatu gerakan tubuh yang dilakukan tanpa sengaja, agak berirama, dan gerakan ototnya melibatkangerakan osilasi dari suatu bagian tubuh ke bagian tubuh lainnya karena merasakan suatu ancaman.

Berdasarkan beberapa definisi dan asumsi tentang kecemasan, maka kecemasan

\footnotetext{
${ }^{15}$ Sutanaya, A. Kecemasan Siswa Terhadap Sekolah ditinjau dari motivasi berprestasi dan konsep diri akademik pada siswa SMA Negeri Denpasar Tahun 2005. Tesis. Singgaraja: Unit Penerbitan IKIP Negeri Singaraja.

${ }^{16}$ Casabbro, J. Text anxiety and What You Can Do About It, Practical Guide for Teachers,Parents, Kids. United States of America: Dude Publishing, 2005) hlm 23.
} 
menghadapi ujian ditinjau dari dua aspek yaitu aspek psikologis (psikis), dan aspek fisiologis (fisik). Aspek psikologis seperti tegang, khawatir, sulit konsentrasi, tidak tenang, takut, dan gelisah. Aspek fisiologis seperti berkeringat dingin, gemetar, tidak dapat tidur, sakit kepala dan jantung berdebar-debar.

\section{EMOTIONAL FREEDOM TECHNIQUE DALAM MENGATASI KECEMASAN SISWA MENGHADAPI UJIAN}

Kecemasan dengan intensitas yang wajar dapat dianggap memiliki nilai positif sebagai motivasi, tetapi apabila intensitasnya sangat kuat dan bersifat negatif justru akan menimbulkan kerugian dan dapat menggangu keadaan fisik maupun psikis individu yang bersangkutan. Apabila individu merespon kecemasan secara tidak rasional, maka individu selalu merasa cemas akan kekurangmampuannya menyelesaikan tugas-tugas tertentu. Dari pemikiran yang irasional tersebut memunculkan kondisi yang cemas pada individu sehingga perlu direduksi dengan berupaya mengkondisikan individu menjadi tenang dan berada dalam keadaan nyaman/rileks sehingga dapat mengikuti ujian dengan tenang tanpa perasaan cemas yang tinggi. Permasalahan kecemasan menghadapi ujian yang dialami siswa jika dibiarkan dan tidak segera diselesaikan akan berkembang dan akan mengangu kehidupannya.

Emotional Freedom Technique (EFT) merupakan sebuah terapi psikologi praktis yang dapat mengurangi kecemasan siswa dalam menghadapi ujian dengan menyelaraskan dan memperbaiki kembali energi dalam tubuh, lewat stimulasi pada titik-titik energi tubuh (tapping). Emotional Freedom Technique (EFT) ini dilakukan melalui beberapa tahap pertama the set up dan the tune in, tahap ini merupakan tahap paling penting yaitu mempersiapkan sistem energi dalam diri konseli untuk melaksanakan tahap berikutnya. The set up dan the tune in merupakan kata-kata sugesti yang dibuat oleh konseli yang pada akhirnya dapat memberikan keyakinan atau kepasrahan untuk dapat mengelola kecemasan yang dialami konseli. Pada saat konseli mengucapkan kalimat sugesti sambil menekan sore spot didada atau karate chop. Tujuannya yaitu untuk memberikan kepastian agar aliran energi tubuh yang dirasakan oleh konseli dapat diarahkan dengan tepat untuk menetralisasi perlawanan psikologis.

Tahap kedua yaitu tapping dimana konseli mengetuk-ngetuk 18 titik meredian ditubuhnya dengan jarinya sambil mengucapkan kata-kata sugesti yang telah dibuatnya pada tahap the set up. Tujuannya yaitu untuk menetralisasi kecemasan yang dirasakannya dalam menghadapi ujian.

Tahap ketiga yaitu nine gamut procedure dimana konseli melakukan sembilan prosedur mulai dari memejamkan mata sampai bergumam selama lima detik sambil mengetuk titik gamut. Tujuannya yaitu untuk mengembalikan keseimbangan energi pada kedua bagian otak untuk bekerja secara harmonis. Beberapa tahap dalam pelaksanaan EFT diatas, kecemasan dapat berkurang ketika siswa melakukan eft secara terus menerus dalam keadaan tenang dan rileks. 


\section{KESIMPULAN}

Masalah kecemasan dalam menghadapi ujian merupakan masalah yang urgent karena kecemasan dapat mengakibatkan berbagai macam ganguan pada diri siswa, menyangkut gangguan fisik maupun psikis yang dapat merugikan dirinya sendiri, orang lain maupun lingkungannya sehinggaa akan mempengaruhi hasil ujian yang diikuti oleh siswa di sekolah, kenyataanya di sekolah-sekolah SMP maupun SMA masih banyak siswa yang tidak dapat mengontrol kecemasannya ketika akan menghadapi ujian sehingga berpengaruh langsung terhadap hasil ujian yang telah diikuti.

Emotional Freedom Technique (EFT merupakan sebuah terapi psikologi praktis yang dapat mengurangi kecemasan siswa dalam menghadapi ujian dengan menyelaraskan dan memperbaiki kembali energi dalam tubuh, lewat stimulasi pada titik-titik energi tubuh (tapping). Emotional Freedom Technique (EFT) ini dilakukan melalui beberapa tahap yaitu, pertama the set up dan the tune in, kedua yaitu tapping, tahap ketiga yaitu nine gamut procedure, tahap keempat yaitu tapping again.

\section{DAFTAR PUSTAKA}

Casabbro, J. 2005. Text anxiety and What You Can Do About It, Practical Guide for Teachers, Parents, Kids. United States of America: Dude Publishing.

Corey, G. 2007. Teori dan Praktek Konseling dan Psikoterapi. Bandung: Rafika Pratama.

Frederick, J. 1983. Relaxation-Induence Anxiety: Paradoxical Anxiety Enhancement Due To Relaxation Training. Jurnal Of Counsulting and Clinical Psychology.

Ghufron, N. \& Rini, R.S. 2011. Teori-Teori Psikologi. Jakarta: Ar-Ruzz Media.

Gunarsa, D.S. 2004. Psikologi Anak Bermasalah. Jakarta: BPK Gunung Mulia.

Hong. 1998. Differential Stability of Individual Differences In State and Trait test anxiety. Learning and individual Learning. 10. 51-70.

Juwono, S. 2012. Buku Terapi EFT (Emotional Freedom Technique). Yogyakarta: NQ. Publising.

Lufi, D. \& Saputra, E. 2004. Test Anxiety And It's Effect on the Personality Of Student with Learning Disabillities. Journal Of Psicological. Vol 27.

Nuryanti. 2010. Efektivitas Brain Gym dalam Menurunkan Kecemasan Siswa Menghadapi Ujian Sekolah. Tesis. Surakarta: Universitas Muhammadiyah.

Safaria, T. \& Nofrans, E.S. 2009. Manajemen Emosi. Jakarta: Bumi Aksara.

Saputra, A. 2011. EFT (Emotional Freedom Tecnique). Yogyakarta: Genius Publisher.

Sutanaya, A. 2005. Kecemasan Siswa Terhadap Sekolah ditinjau dari motivasi berprestasi dan konsep diri akademik pada siswa SMA Negeri Denpasar Tahun 2005. Tesis. Singgaraja: Unit Penerbitan IKIP Negeri Singaraja.

Zaki, M. 2012. 5 Terapi Sehat. Jakarta: PT. Elex Media Komputindo. 